\title{
HLA class II antigens associated with systemic lupus erythematosus in black South Africans
}

\author{
Martin Rudwaleit, Mohammed Tikly, Kathryn Gibson, Kevin Pile, Paul Wordsworth
}

\begin{abstract}
Objective-To assess the associations of HLA class II antigens with systemic lupus erythematosus (SLE) in black South Africans.

Methods-HLA-DRB1 genotype frequencies assigned by polymerase chain reaction (PCR) amplification and sequence specific oligonucleotide probes were compared between 49 black SLE patients from Baragwanath Hospital and 87 ethnically matched controls. HLA-DQA1 and -DQB1 genotypes were also assigned in 45 of the SLE patients and 74 controls by PCR using sequence specific primers.

Results-HLA-DRB1 ${ }^{0} 02$ was increased in the patients compared with controls (odds ratio $=3 \cdot 67 ; 95 \%$ confidence interval $=1 \cdot 49$ to $9.02 ; p<0.005)$. HLA-DQB1*0201 was not associated with development of the disease itself, but was associated with the presence of Ro antibodies $(p=0.01)$. HLADRB1*03 was less strongly linked to DQB1*02 in this population than in white populations and was not associated with SLE.
\end{abstract}

Conclusions-In black South Africans there is evidence for a locus on DR2 haplotypes contributing to SLE. Another gene, possibly HLA-DQB1*02, not linked to $D R 2$ is involved in the subset of patients exhibiting Ro antibodies.

(Ann Rheum Dis 1995; 54: 678-680)

Genetic susceptibility to systemic lupus erythematosus (SLE) is suggested by population and family studies, particularly as the concordance rate in monozygotic twins is at least 10 -fold that of dizygotic twins. ${ }^{1}$ The genes involved in SLE have not yet been identified with certainty, but most studies implicate genes within the major histocompatibility complex.

The study of different ethnic groups can help to identify more precisely which genes are involved in disease susceptibility, for two reasons: first, there are interethnic differences in the frequencies of particular disease associated alleles; second, different haplotypic combinations of alleles in different races may allow the primary associations with disease to be defined. In white patients with SLE the most consistent findings have been increases in HLA-DR3, DR2, or both. ${ }^{2-4}$ However, in black Americans, associations have been variously described with DR3, ${ }^{5}$ both DR2 and DR3, ${ }^{6}$ and DR7, though these have not been confirmed in other studies. ${ }^{489}$ Some of these apparent inconsistencies could be accounted for by ethnic heterogeneity among the patients and controls, reflecting their diverse African origins. It has also been suggested that in white subjects there may be an association with HLA-DQA ${ }^{\star} 0501{ }^{2}{ }^{2}$ We have therefore investigated HLA-DR, -DQA, and -DQB genotype frequencies in black SLE patients from South Africa who constitute a more homogeneous ethnic group than black immigrants in North America.

\section{Patients and methods}

PATIENTS

Forty nine black South African (Sotho and Zulu) patients with SLE (46 female) attending Baragwanath Hospital were studied and compared with 87 geographically and ethnically matched controls. All patients met four or more 1982 criteria of the American Rheumatism Association for the diagnosis of SLE. Table 1 shows their clinical details. Genomic DNA was prepared from frozen peripheral blood samples.

\section{HLA-DR TYPING}

Patients and controls were typed for HLADRB1 alleles by polymerase chain reaction (PCR) and sequence specific oligonucleotide (SSO) probes. In contrast to our previous procedure $^{10}$ the nitrocellulose filters were hybridised sequentially to 14 SSO probes labelled with digoxigenin. Specific binding was detected by chemiluminescence using Lumigen (Boehringer) according to the manufacturer's instructions.

Table 1 Clinical and serological data from black SLE patients from South Africa

\begin{tabular}{ll}
\hline Clinical features & SLE patients $(n=49)$ \\
\hline Age (yr) (mean (range)) & $34 \cdot 7(13-61)$ \\
Disease duration (yr) (mean (range)) & $3.4(0 \cdot 2-20)$ \\
Female:male & $46: 3$ \\
Arthritis & $38(77 \%)$ \\
Renal & $19(39 \%)$ \\
CNS & $13(26 \%)$ \\
Serositis & $15(30 \%)$ \\
Photosensitivity & $12(24 \%)$ \\
Malar rash & $27(55 \%)$ \\
Discoid lupus & $13(26 \%)$ \\
Leucopenia & $18(37 \%)$ \\
ANA & $49(100 \%)$ \\
Antibodies to: & \\
DNA & $29(59 \%)$ \\
Ro (SS-A) (n=41) & $25(61 \%)$ \\
La (SS-B) (n=41) & $13(31 \%)$ \\
Sm $(n=44)$ & $22(50 \%)$ \\
RNP $(n=44)$ & $32(72 \%)$ \\
\hline
\end{tabular}

CNS = Central nervous system; ANA = antinuclear antibodies; RNP = ribonucleoprotein. 
HLA-DQA AND -DQB TYPING

PCR amplification with sequence specific primers (SSP) was used to define HLADQA $1^{11}$ and $-D Q B 1$ alleles $^{12}$ in an unselected subset of 45 patients and 74 controls. There are minor weaknesses in this system for the unequivocal typing of the eight $\mathrm{DQB} 1{ }^{\star} 06$ alleles. Four PCR SSP reactions were used to distinguish four groups of alleles, corresponding to: i) $\mathrm{DQB} 1^{\star} 0601$; ii) $\mathrm{DQB} 1^{\star} 0602$ or ${ }^{\star} 0603$; iii) $\mathrm{DQB} 1^{\star} 0606$; iv) $\mathrm{DQB} 1{ }^{\star} 0603,{ }^{\star} 0604,{ }^{\star} 0605,{ }^{\star} 0606,{ }^{\star} 0607$ or $\star 0608$. Consequently, DQ6 homozygous individuals assigned as DQB $1{ }^{\star} 0603-8 /$ DQB $1{ }^{\star} 0602 / 3$ could not be typed unequivocally. Although our results from the South African control subjects strongly suggested that virtually all of these alleles would be ${ }^{\star} 0602$ or ${ }^{\star} 0603$, we preferred not to make such inferences in the small number of ambiguous $\mathrm{DQB} 1^{\star} 06$ homozygotes. Therefore we excluded four patients and nine controls from the analysis of $\mathrm{DQB} 1{ }^{\star} 0602$ risk estimates.

\section{STATISTICAL ANALYSIS}

The significance of differences between the groups was assessed by the $\chi^{2}$ or Fisher's exact test as appropriate. The cross product ratio was used to calculate the odds ratio (OR) defining the strength of the association between a risk factor and the disease and the $95 \%$ confidence interval (CI). Adjusted risk estimates for DR3 were calculated with stratification on DR2, and the empirical logistic method ${ }^{13}$ was used to establish the primary association in cases where two linked HLA class II genes (for example DR3 and DQ2) were both associated with the disease.

\section{Results}

Table 2 lists the HLA-DRB1 and -DQB1 genotype frequencies. At the HLA-DRB1 locus there was a significant association with $\mathrm{DRB} 1{ }^{\star} 02 \quad(\mathrm{OR}=3.67,95 \% \quad \mathrm{CI}=1.49$ to $9.02 ; \mathrm{p}<0.005)$ but not $\mathrm{DRB} 1^{\star} 03$. HLADQA $1{ }^{\star} 0102 / 3$ appears to be linked to DRB ${ }^{\star} 02$ in this population (data not shown), and was consequently also slightly increased $(75 \% v 64 \%$, not significant), but HLADQA $1{ }^{\star} 0501$ was not increased. After the ambiguous $\mathrm{DQB1}{ }^{\star} 06$ homozygotes were excluded (see Methods), a significant increase in DQB $1^{\star} 0602$ was seen in the patients compared with the controls (23/41 $v$ 20/65; $\mathrm{OR}=2 \cdot 88,95 \% \quad \mathrm{CI}=1.20$ to $6.87 ; \mathrm{p}<$ $0.025)$.

HLA-DRB $1^{\star} 02$ and $\mathrm{DQB} 1{ }^{\star} 0602$ are both associated with SLE in this population. We could not determine an independent effect from either of these two alleles after stratification on $\mathrm{DRB} 1{ }^{\star} 02$ and $\mathrm{DQB} 1{ }^{\star} 0602$. However, using the empirical logistic method HLA-DRB $1{ }^{\star} 02$ appears to be the more relevant allele: the effect of $\mathrm{DRB} 1^{\star} 02$ (empirical logit $2 \cdot 7034$, variance $1 \cdot 5013$, p two tailed 0.026 ) was significant, in contrast with DQB1*0602 (empirical logit 0.835, variance
Table $2 H L A-D R B 1$ and $-D Q B 1$ genotype frequencies in $S L E$ patients and controls from South Africa

\begin{tabular}{|c|c|c|c|c|}
\hline \multirow[t]{2}{*}{ Genotype } & \multicolumn{2}{|c|}{$S L E$} & \multicolumn{2}{|c|}{ Controls } \\
\hline & $n$ & $\%$ & $n$ & $\%$ \\
\hline $\mathrm{DRB} 1^{\star} 01$ & 3 & $6 \cdot 1$ & 6 & $6 \cdot 8$ \\
\hline DRB $11^{\star} 02$ & 17 & $34 \cdot 7 \ddagger$ & 11 & $12 \cdot 6$ \\
\hline DRB $1 \star 03$ & 19 & $38.7^{+}$ & 31 & $35 \cdot 6$ \\
\hline DRB $1 * 04$ & 4 & $8 \cdot 1$ & 5 & $5 \cdot 7$ \\
\hline DRB $1 \star 07$ & 5 & $10 \cdot 2$ & 11 & $12 \cdot 6$ \\
\hline $\mathrm{DRB} 1 \star 08$ & 4 & 8.1 & 9 & $10 \cdot 3$ \\
\hline DRB $1 * 09$ & 2 & $4 \cdot 0$ & 2 & $2 \cdot 3$ \\
\hline DRB $1 * 10$ & 1 & $2 \cdot 0$ & 1 & $1 \cdot 1$ \\
\hline DRB $1^{\star} 11$ & 14 & 28.5 & 31 & 35.6 \\
\hline $\mathrm{DRB} 1 * 12$ & 1 & $2 \cdot 0$ & 7 & $8 \cdot 0$ \\
\hline $\mathrm{DRB} 1 * 13$ & 14 & 28.5 & 29 & $33 \cdot 3$ \\
\hline $\mathrm{DRB} 11^{\star} 14$ & 1 & $2 \cdot 0$ & 1 & $1 \cdot 1$ \\
\hline $\mathrm{DQB1} 1^{\star} 02$ & 16 & 35.5 & 23 & $31 \cdot 1$ \\
\hline $\mathrm{DQB} 1{ }^{\star} 04$ & 9 & 20.0 & 14 & 18.9 \\
\hline $\mathrm{DQB} 1{ }^{\star} 05$ & 5 & $11 \cdot 1$ & 17 & $23 \cdot 0$ \\
\hline DQB1 $1{ }^{\star} 06$ & 33 & $73 \cdot 3+$ & 41 & $55 \cdot 4$ \\
\hline $\mathrm{DQ}^{\star} 0602$ & 23 & $51 \cdot 1+\dagger$ & 20 & $27 \cdot 0$ \\
\hline $\mathrm{DQ}{ }^{\star} 0603-{ }^{\star} 0608 \rrbracket$ & 6 & $13 \cdot 3^{11}$ & 12 & $16 \cdot 2$ \\
\hline $\mathrm{DQ}^{\star} 0601$ & 0 & & 0 & \\
\hline $\mathrm{DQB} 1^{\star} 07$ & 7 & $15 \cdot 5$ & 24 & $33 \cdot 8$ \\
\hline $\mathrm{DQB} B 1^{\star} 08$ & 0 & & 3 & $4 \cdot 0$ \\
\hline DQB $1{ }^{\star} 09$ & 1 & $2 \cdot 2$ & 0 & \\
\hline
\end{tabular}

DRB1 genotypes were assigned in 49 SLE patients and 89 controls; DQB1 genotypes were assigned in 45 SLE patients and 74 controls.

$\ddagger \chi^{2}=8.02, \mathrm{OR}=3.67$ (95\%CI 1.49 to 9.02$), \mathrm{p}<0.005$.

$+\chi^{2}=3 \cdot 10$, OR $=2 \cdot 21(95 \% \mathrm{CI} 1.09$ to $5 \cdot 78), \mathrm{p}<0.06$

$+t x^{2}=5.68$, OR $=2.88(95 \%$ CI $1 \cdot 20$ to 6.87$), p<0.025$. Data derive from the statistical analysis of 41 patients and 65 controls (see also text).

Individuals assigned in this table as $\mathrm{DQB}{ }^{\star}{ }^{\star} 0603-8$ can be DQB $1{ }^{\star} 0603,{ }^{\star} 0604,{ }^{\star} 0605,{ }^{\star} 0606,{ }^{\star} 0607$, or ${ }^{\star} 0608$.

1.5013, p two tailed $0 \cdot 49)$, without likelihood of a $\mathrm{DRB} 1^{\star} 02 / \mathrm{DQ}^{\star} 0602$ interaction (empirical logit $-0 \cdot 835$, variance $1 \cdot 5013$, p two tailed $0 \cdot 49$ ), indicating that $\mathrm{DRB} 1^{\star} 02$ represents the stronger association in this population.

Clinical manifestations of SLE were not associated with particular HLA genotypes, but there was a significant association between HLA-DQB ${ }^{\star} 02$ and Ro antibodies. Thus in the subgroup of 37 patients who had been typed for anti-Ro and for whom an unequivocal $\mathrm{DQ}$ type could be assigned, 12/22 anti-Ro positive patients were also $\mathrm{DQB} 1^{\star} 02$ positive (OR $=7 \cdot 8 ; 95 \% \mathrm{CI}=1 \cdot 24$ to $48 \cdot 89$, $\mathrm{p}=0.011)$. The association between anti-Ro and DR3 was somewhat weaker $(p=0.06)$.

\section{Discussion}

The increase in HLA-DR2 in our study is reflected in only one study of black SLE patients from North America. ${ }^{6}$ Although two studies have shown an association with DR $3,{ }^{5}{ }^{6}$ at least three others have shown no HLA-DR or -DQ associations. ${ }^{489}$ Clinical heterogeneity between the groups studied has been invoked to explain this, but when studying populations of African origin one must also take account of the potential for substantial genetic variation. ${ }^{14}$ Therefore, ethnic heterogeneity of the black North Americans in these studies could mask real associations-a problem we have overcome by selecting SLE patients and controls with careful regard to their ethnic affiliations. The association of SLE with HLADQB $1^{\star} 0602$ in this population appears to be secondary to linkage disequilibrium with HLA$\mathrm{DRB} 1{ }^{\star} 02$, as the empirical logistic test favours the latter allele as being of primary importance. 
The recently suggested association of SLE with HLA-DQA1*0501 in white populations ${ }^{2}$ does not appear to cross racial boundaries, as in our study only $32 \%$ of the patients were positive for DQA ${ }^{\star}{ }^{\star} 0501$, compared with $37 \%$ of the controls. In contrast, the association of DR2 with SLE does cross racial boundaries, as positive associations have also been reported previously in white and Asian populations. ${ }^{15}$

The frequencies of autoantibodies to Ro $(61 \%)$, ribonucleoprotein $(72 \%)$, and $\mathrm{Sm}$ $(50 \%)$ in these South Africans with SLE are greater than has been previously observed in black or white Americans. ${ }^{4}{ }^{79} \mathrm{HLA}-\mathrm{DQB} 1{ }^{\star} 02$ and, to a lesser extent $\mathrm{DRB} 1^{\star} 03$, were associated with antibodies to Ro, but not with the disease itself. An association of both these alleles with Ro antibodies in SLE patients has been reported previously, ${ }^{9}$ but it is likely that the $\mathrm{DRB} 1{ }^{\star} 03$ association is secondary to linkage disequilibrium with $\mathrm{DQB} 1^{\star} 02$. The variable strength of this linkage disequilibrium in different racial groups could also account for the variable association of $\mathrm{DRB} 1{ }^{\star} 03$ with SLE in different races. Thus among the $\mathrm{DRB} 1^{\star} 03$ bearing haplotypes in the black South Africans, only $50 \%$ were also $\mathrm{DQB} 1{ }^{\star} 02$ (data not shown), compared with 100 per cent in white subjects. The greater diversity of DR3 haplotypes in black South Africans may indicate that only a minority bear the putative 'SLE gene' in contrast with white subjects. The nature of this HLA-linked gene remains to be established, but would include the C4A locus which has been incriminated in the aetiology of SLE in other studies in white populations. ${ }^{24}$

In conclusion, there is evidence from our results for an SLE susceptibility locus on a DR2 haplotype in black South Africans. Furthermore, DQB $1^{\star} 02$ which is not linked to $\mathrm{DRB} 1{ }^{\star} 02$ is associated with the presence of Ro antibodies, which suggests the existence of at least two unlinked MHC loci contributing to SLE in this population.
M Rudwaleit is supported by a grant from the Deutschen Akademischen Austauschdienst (DAAD). The authors are grateful for the financial support of the Arthritis and Rheumatism Council.

Presented in part at the XIth Annual General Meeting of the British Society for Rheumatology in Brighton, 20-22 April 1994.

1 Deapen D, Escalante A, Weinrib L, et al. A revised estimate of twin concordance in systemic lupus erythematosus. of twin concordance in system

2 Davies E J, Hillarby M C, Cooper R G, et al. HLA-DQ, DR and complement $\mathrm{C4}$ variants in systemic lupus erythematosus. Br F Rheumatol 1993; 32: 870-5.

3 Hartung K, Baur M P, Coldeway R, et al. Major histocompatibility complex haplotypes and complement $\mathrm{C} 4$ alleles in systemic lupus erythematosus. $\mathcal{f}$ Clin Invest 1992; 90: 1346-51.

4 Howard P F, Hochberg M C, Bias W B, Arnett F C, McLean $\mathrm{R}$ H. Relationship between $\mathrm{C} 4$ null genes, HLA-DR region antigens, and genetic susceptibility to systemic lupus erythematosus in caucasian and black Americans. Am $\mathcal{F}$ Med 1986; 81: 187-92.

5 Alarif L I, Ruppert G B, Wilson R, Barth W F. HLA-DR antigens in blacks with rheumatoid arthritis and systemic lupus erythematosus. $\mathcal{f}$ Rheumatol 1982; 10: 297-300.

6 Kachru R B, Sequeira W, Mittal K K Siegel M E Telischi M. A significant increase of HLA-DR3 and Telischi M. A significant increase of HLA-DR3 and
DR2 in systemic lupus erythematosus among blacks. DR2 in systemic lupus erythe

7 Wilson W A, Scopelitis E, Michalski J P. Association of HLA-DR7 with both antibody to SSA (Ro) and disease susceptibility in blacks with systemic lupus erythematosus. F Rheumatol 1984; 11: 653-7.

8 Olsen M L, Goldstein R, Arnett F C, Duvic M, Pollack M Reveille J D. C4 gene deletion and HLA associations in black Americans with systemic lupus erythematosus. Immunogenetics 1989; 30: 27-33.

9 Reveille J D, Schrohenloher R T, Acton R T, Barger B O. DNA analysis of HLA-DR and DQ genes in American DNA analysis of HLA-DR and DQ genes in American 1989; 32: 1243-51.

10 Wordsworth B W, Allsopp C E M, Young R P, Bell J I. HLA-DR typing using DNA amplification by the polymerase chain reaction and sequential hybridization to sequence-specific oligonucleotide probes. Immunogenetics 1990; 32: 413-8.

11 Olerup O, Aldener A, Fogdell A. HLA-DQB1 and -DQA1 typing by PCR amplification with sequence-specific primers (PCR-SSP) in 2 hours. Tissue Antigens 1993; 41 119-34.

12 Bunce M, Taylor C J, Welsh K I. Rapid HLA-DQB typing by eight PCR amplifications with sequence-specific primers (PCR-SSO). Hum Immunol 1993; 37: 201-6.

13 Green J R, Chiew M K, Low H C, Woodrow J C. The association between HLA antigens and the presence of association between HLA antigens and the

14 Hammond M G, Du Toit E D, Sachs J A, Kaplan C, Mbayo K. W5.4 HLA in southern African populations. In: Tsuji $\mathrm{K}$, Aizawa M, Sasazuki T, eds. HLA 1991 Proceedings of the eleventh international histocompatibility workshop and conference. Oxford: Oxford University Press, 1991 ; 636-8.

15 Doherty D G, Ireland R, Demaine A G, et al. Major histocompatibility complex genes and susceptibility to systemic lupus erythematosus in southern Chinese. Arthritis Rheum 1992; 35: 641-6. 